\title{
Review Article \\ Renal Transplantation Is Associated with Improved Clinical Outcomes in Nephrogenic Systemic Fibrosis
}

\author{
Rabi Yacoub, ${ }^{1}$ Kiran Kandukurti, ${ }^{1}$ and Mandip Panesar ${ }^{1,2}$ \\ ${ }^{1}$ Division of Nephrology, Department of Internal Medicine, State University of New York at Buffalo, Buffalo, NY 14215, USA \\ ${ }^{2}$ The Regional Center of Excellence for Transplantation and Kidney Care, Erie County Medical Center, 462 Grider Street, \\ Buffalo, NY 14215, USA
}

Correspondence should be addressed to Mandip Panesar; mpanesar@ecmc.edu

Received 11 February 2013; Accepted 20 March 2013

Academic Editors: A. Rydzewski, P. Toniutto, and A. Van Eyk

Copyright (C) 2013 Rabi Yacoub et al. This is an open access article distributed under the Creative Commons Attribution License, which permits unrestricted use, distribution, and reproduction in any medium, provided the original work is properly cited.

\begin{abstract}
Nephrogenic systemic fibrosis is a debilitating disorder seen in chronic kidney disease patients and is characterized by stiffening of the joints and thickening of the skin. Treatment options are limited, but some patients have had an improvement of their clinical symptoms after renal transplantation and the use of immunosuppression. Although there is a variable response to renal transplantation, it is currently unknown what factors promote a favorable outcome. Our objective was to evaluate if the response to renal transplantation was superior to other treatment modalities and to determine which characteristics allowed for a positive response to occur. We retrieved the data from the literature of 298 reported patients, compared the response to renal transplantation and to other treatments, and analyzed their characteristics. We found that more patients had a higher response to renal transplantation, as determined by softening of the skin and improved joint mobility, and among those that did respond, they had a shorter dialysis vintage. We suggest that if renal transplantation is to be considered as a treatment modality, it should be initiated at the earliest possible in the course of the disease to achieve maximum clinical benefit.
\end{abstract}

\section{Introduction}

Nephrogenic systemic fibrosis (NSF) is primarily seen in chronic kidney disease $(\mathrm{CKD})$ patients and is characterized by large areas of hardened skin with slightly raised plaques, papules, and hyperpigmentation. Biopsies of the affected areas show increased numbers of fibroblasts, alteration of the normal pattern of collagen bundles, and often increased dermal deposits of mucin [1]. The skin may have a "cobblestone" [2], "woody" [3, 4], or peau d' orange appearance [5]. These lesions may be pruritic and accompanied by sharp pain or burning sensations $[3,6]$. Movement of the joints may be so severely limited by the fibrosis that the flexibility is lost.

The first cases were noted between 1997 and 2000 in hemodialysis (HD) patients or patients with a failed renal allograft who developed severe skin indurations that were initially thought to be scleromyxedema [7, 8]. Since Grobner reported a correlation between the use of gadolinium $(\mathrm{Gd})$ in end-stage renal disease (ESRD) patients and NSF [9], additional reports supporting this correlation have been published $[10,11]$. It is now recognized that low-stability gadolinium-based contrast agents, in the presence of permissive factors, most likely trigger the disease. The prevalence of NSF after exposure to gadodiamide (Omniscan) has been reported to be between $3 \%$ and $7 \%$ in patients with reduced renal function in several different studies [12-14]. In a study evaluating ESRD patients over an 18-month period [15], it was found that the incidence of NSF was 4.3 cases per 1000 patient years and each radiologic study using gadolinium presented a $2.4 \%$ risk for developing the disease. Other studies have shown that the exposure to gadolinium-based contrast agents was associated with an increased risk of developing cutaneous changes of NSF (odds ratio, 14.7; 95\% confidence interval, 1.9-117.0) compared with patients who were not exposed to gadolinium [16]. Patients suffering from NSF were found to have higher mortality rate compared to matched controls with no cutaneous lesions. It was found to be as high as $48 \%$ over a 24-month followup [16]. As of May 2011, over 335 cases of NSF have been reported to the International NSF Registry at Yale University [1]. 
There is no proven treatment available to patients suffering from NSF. Although various treatments such as highdose intravenous immunoglobulin [17], plasmapheresis [18], extracorporeal photopheresis (ECP) $[19,20]$, imatinib [21], and sodium thiosulfate (STS) [22] have been reported to provide benefit, it has only been shown in a limited number of cases, and therefore no generalizations can be made. However, the progressive course of NSF may be altered by improving kidney function as the remission of NSF has been described in patients who recovered from acute kidney injury $[4,23,24]$ or after receiving a kidney transplant [25]. The response to transplantation has been variable ranging from a complete resolution of symptoms $[9,26]$ to minimal or no improvement reported in some patients [27, 28]. Although there are more documented cases of clinical improvement of NSF after renal transplantation, it is still unknown what factors confer a favorable response to transplantation versus those that do not. The database of 298 patients that we have formulated from the existing literature compares the response to renal transplantation and to other treatments, with an analysis of their characteristics. We attempted to determine if there were any patient factors that could predict a better response to transplantation and if this treatment modality was superior to others with respect to better clinical outcomes.

\section{Patients and Methods}

PubMed, MEDLINE, Google, Google scholar, and Embase databases were searched for articles including early release publications, limited to a date range of January 1, 2000 through May 1, 2011. Keywords and medical subject heading (MeSH) were used in the search. MeSH term used was "nephrogenic fibrosing dermopathy" and search keywords included "nephrogenic systemic fibrosis," "nephrogenic fibrosing dermopathy," "case report," "dialysis-associated dermatopathy", "renal transplant" and "survival." Abstracts of retrieved citations were reviewed and prioritized by relevance. Full articles were obtained and reference lists were reviewed for additional articles when appropriate. Data from these studies on benefits of different NSF treatment modalities on both patient survival and disease response along with patients' characteristics were extracted.

Inclusion criteria incorporated articles describing a newly or previously diagnosed case of NSF, delineation of the management, NSF response to treatment, time of followup, and patient outcomes. The exclusion criteria included review articles, articles with insufficient data, and papers limited to biopsy studies only due to the lack of clinical information. The manuscripts reviewed were not just limited to English; even non-English language papers were translated and analyzed. Both the dialysis-dependent patients as well as patients who were not on maintenance dialysis were included. To reduce the chance of duplication, data regarding patient characteristics were compared to the articles wherein they were originally reported. Treatment modalities of NSF patients were divided into four groups, namely, those who either continued on maintenance dialysis or received no treatment at all (T1), those who received treatment other than renal transplantation (T2), patients who received only renal transplantation as a treatment modality (T3), and those patients who received alternative treatment initially which was followed later by renal transplantation (T4). The unanalyzed and unreported data from the original publications were considered as missing data.

Time to treat was defined as the duration between the beginning of NSF symptoms and any treatment provided to each group, with zero weeks being the time to treat in patients who received maintenance dialysis only, and time to dialysis for those who were initiated on dialysis either as maintenance dialysis or as a treatment for acute kidney injury (AKI) after NSF was diagnosed and did not receive any other NSF directed therapy (in group T1). Improvement was defined as a complete resolution of symptoms, softening of the skin, improved joint mobility, and improved functional status, as outlined in respective publications. Decrease of edema alone was not considered as a response to treatment. Skin biopsy after treatment was neither performed nor reported in the original case reports. Detailed biopsy results and immunohistochemical staining were reported in only a few articles. Most of the cases that were labeled as NSF were initially biopsy proven NSF.

Statistical analysis was conducted using NCSS statistical program. All categorical variables were analyzed for statistical significance using chi-square test. Noncategorical variables were analyzed using analysis of variance. All noncategorical variables were presented as mean \pm standard error (SE) of mean. To evaluate the outcome of various treatments on NSF, data were analyzed using Cox-regression analysis with response to treatment considered as an event, no response during followup as censored, and follow up as reported in the literature using the Efron method to analyze time ties. Hazard ratio (HR) was calculated to evaluate the response rate and two-sided log rank probability test $(P$ value $)$ to evaluate for statistical significance.

\section{Results}

Of the articles retrieved, 157 were case reports, and of these, 95 had sufficient information with respect to the inclusion criteria $[2,3,5,6,9,10,14-16,18,19,21-23,25,26,28-106]$. After application of the inclusion and exclusion criteria, 298 patients were selected (Figure 1).

Patients' age range was from 8 to 87 years with a mean of $51.4 \pm 0.9$ years (mean $\pm \mathrm{SE})$, and $46.89 \%(N=128)$ were male. The response to treatment was monitored for an average of $58.2 \pm 4.0$ weeks (1-336 weeks), and patient survival was followed up to an average of $58.8 \pm 4.0$ weeks (1-336 weeks). The time until any treatment was initiated following the diagnosis of NSF was $16.1 \pm 3.1$ weeks (0-364 weeks). Patients on maintenance dialysis were 255 (86.4\% on HD) for a duration of $48.7 \pm 4.2$ months ( $0-385$ months). After extensive review of patients' medication and imaging studies, authors of the original case reports reported 153 patients who had Gd exposure, while 15 patients were never exposed to Gd.

T3 and T4 patients were younger when compared to the other two groups $(P=0.019)$; they also had the 


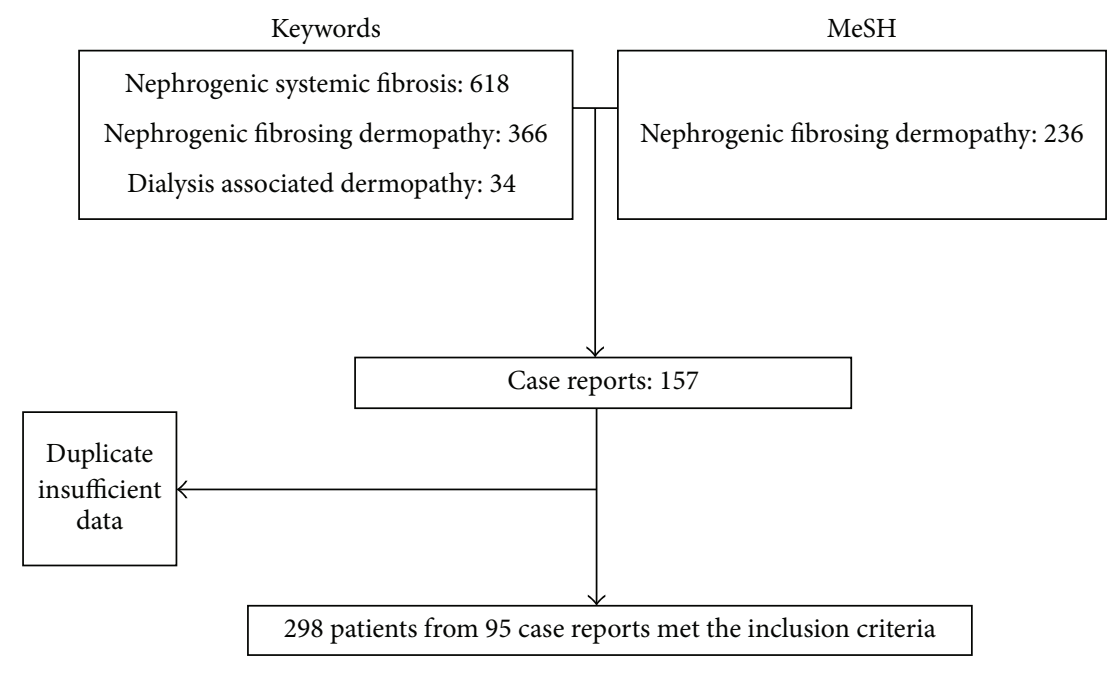

FIGURE 1: Flow diagram.

longest duration until treatment $(P<0.001)$. No statistically significant difference was found among the groups regarding gender, race, dialysis vintage, prior renal transplantation, and followup duration. All patients who received renal transplantation regardless of previous other treatments had ESRD at the time of NSF diagnosis (Table 1). Patients who received renal transplantation showed significant improvement when compared to the other two groups. Group T2 (i.e., treatments other than transplantation) also demonstrated a higher improvement rate when compared to no treatment. The same results were retrieved after correcting for age and time to treat. Table 2 compares all the treatment modalities.

The differences in patients' characteristics between those who responded and those who did not during the followup period were also analyzed (Table 3 ). Patients who responded to any treatment were younger, had lesser dialysis vintage, had a longer time to treat, and had a higher rate of receiving a renal transplant previously. This longer time to treat effect contributed to a better outcome as observed among those renal transplantation patients who had longer time to treat.

Of the 26 patients treated with renal transplantation, data regarding dialysis vintage were available on only 23 . Patients who were dialyzed for less than four years had a better response rate after renal transplantation. No difference was found regarding age, gender, duration to treat, and prior renal transplantation. Only eight patients' race was reported therefore making the racial distribution analysis imprecise (Table 4). An interesting observation regarding the use of any other treatment prior to transplantation was noticed. Eight out of nine patients treated only with renal transplantation improved compared to 11 of the 17 patients who received renal transplantation preceded by other NSF specific treatment. Those patients who only received a renal allograft were dialyzed for $31.2 \pm 21.7$ compared to $44.8 \pm 15.8$ months, were transplanted earlier $(66.8 \pm 13.5$ compared to $80.4 \pm 9.9$ weeks) and showed a faster clinical response (20.5 compared to 78.6 weeks $(P>0.05$ for all $))$.

\section{Discussion}

Patients with NSF generally have a poor clinical course as the fibrosis affecting the joints and skin often leads to contractures, pain, and immobility. Although various treatments have been tried on patients, most have resulted in variable clinical responses, and overall consistency is lacking. For instance, the response to ECP, which induces monocytederived tumor necrosis factor-alpha and suppresses collagen synthesis and enhances collagenase production, was demonstrated in a case report, wherein 2 out of 3 patients had a marked resolution of skin lesions and normalization of skin distensibility after undergoing from 8 to 16 cycles at two to four week intervals [48]. In another case report [19], a patient who was two years after kidney transplantation showed significant improvement of the sclerodermiform brownish plaques on her extremities after 4 cycles of ECP. Although ultraviolet-A phototherapy (UV-A) has the ability to inhibit procollagen synthesis in human skin [107], the response has been variable $[8,19,47,108,109]$. Furthermore, there has been improvement reported after three to five days of plasmapheresis treatment in three patients [53]. A decrease in the transforming growth factor-beta-1 levels following plasmapheresis presumably led to the amelioration of this clinical condition. Imatinib, a treatment modality used in patients with chronic myelogenous leukemia (CML) and noted to cause a regression of concomitant bone marrow, pulmonary, hepatic, and kidney fibrosis, has also been tried [110]. Studies have shown a strong dose-dependent in vitro and in vivo inhibition of the synthesis of major dermal extracellular matrix proteins [111]. Kay and High [21] treated two patients with stage $5 \mathrm{CKD}$ and NSF with oral imatinib mesylate at a dosage of $400 \mathrm{mg} /$ day and found that imatinib mesylate treatment decreased fibrosis and resulted in a relatively rapid and steady improvement of the skin changes. However, these skin changes recurred after the discontinuation of the drug. Henceforth, they recommended 
TABLe 1: Patients' basic characteristics.

\begin{tabular}{|c|c|c|c|c|c|c|c|c|c|}
\hline \multirow{2}{*}{ Noncategorical variables } & \multicolumn{2}{|c|}{$\mathrm{T} 1$} & \multicolumn{2}{|c|}{$\mathrm{T} 2$} & \multicolumn{2}{|c|}{ T3 } & \multicolumn{2}{|c|}{$\mathrm{T} 4$} & \multirow{2}{*}{$P$} \\
\hline & Mean & SE & Mean & SE & Mean & SE & Mean & SE & \\
\hline Age in years & 53.9 & 1.1 & 48.6 & 1.6 & 45.4 & 5.3 & 43.4 & 3.9 & 0.019 \\
\hline Duration to treat in weeks & 2.8 & 3.3 & 25.6 & 5.9 & 66.8 & 13.5 & 80.4 & 9.9 & $<0.001$ \\
\hline Followup duration in weeks & 61 & 5.6 & 53.6 & 6.9 & 20.5 & 20.2 & 78.7 & 14.3 & 0.035 \\
\hline Dialysis duration in months & 49.9 & 5.5 & 49.5 & 7.4 & 31.2 & 21.7 & 44.8 & 15.8 & 0.979 \\
\hline \multirow{2}{*}{ Categorical variables } & \multicolumn{2}{|c|}{$\mathrm{T} 1$} & \multicolumn{2}{|c|}{$\mathrm{T} 2$} & \multicolumn{2}{|c|}{$\mathrm{T} 3$} & \multicolumn{2}{|c|}{$\mathrm{T} 4$} & $P$ \\
\hline & $N$ & $\%$ & $N$ & $\%$ & $N$ & $\%$ & $N$ & $\%$ & $P$ \\
\hline \multicolumn{10}{|l|}{ Gender (25 missing data) } \\
\hline Male & 76 & 46.3 & 43 & 50 & 1 & 16.7 & 8 & 47.1 & \multirow{2}{*}{0.465} \\
\hline Female & 88 & 60.7 & 43 & 50 & 5 & 83.3 & 9 & 52.9 & \\
\hline \multicolumn{10}{|l|}{ Race (204 missing data) } \\
\hline White & 41 & 68.3 & 20 & 76.9 & 2 & 50 & 3 & 75 & \multirow{3}{*}{0.22} \\
\hline African American & 11 & 18.3 & 1 & 3.8 & 2 & 50 & 0 & 0 & \\
\hline Others & 8 & 13.3 & 5 & 19.2 & 0 & 0 & 1 & 25 & \\
\hline \multicolumn{10}{|c|}{ Prior renal transplantation ( 2 missing data) } \\
\hline Prior transplantation & 36 & 19.8 & 26 & 29.5 & 1 & 11.1 & 4 & 23.5 & \multirow{2}{*}{0.268} \\
\hline No prior transplantation & 146 & 80.2 & 62 & 70.5 & 8 & 88.9 & 13 & 76.5 & \\
\hline ESRD at diagnosis (7 missing data) & 166 & 93.3 & 69 & 79.3 & 9 & 100 & 17 & 100 & 0.001 \\
\hline
\end{tabular}

T1: patients who received no treatment other than dialysis. T2: patients who received NSF specific treatment other than renal transplantation. T3: patients who received only renal transplantation. T4: patients who received NSF specific treatment followed by renal transplantation. SE: standard error. $P$ : probability value.

TABLE 2: Improvement rate between treatment modalities.

\begin{tabular}{|c|c|c|c|c|c|c|}
\hline \multirow{2}{*}{ Groups } & \multicolumn{3}{|c|}{ Without adjustments } & \multicolumn{3}{|c|}{ After adjustment for age and time to treat } \\
\hline & HR & CI 95\% & $P$ & HR & CI 95\% & $P$ \\
\hline $\mathrm{T} 2$ versus $\mathrm{T} 1$ & 7.69 & $3.69-15.97$ & $<0.0001$ & 9.69 & $3.52-26.62$ & $<0.0001$ \\
\hline $\mathrm{T} 3$ versus $\mathrm{T} 1$ & 25.24 & $9.16-69.54$ & $<0.0001$ & 27.75 & $8.12-94.88$ & $<0.0001$ \\
\hline $\mathrm{T} 4$ versus $\mathrm{T} 1$ & 6.59 & $2.69-16.14$ & $<0.0001$ & 8.41 & $2.38-29.71$ & $<0.001$ \\
\hline $\mathrm{T} 3$ versus $\mathrm{T} 2$ & 3.28 & $1.43-7.52$ & 0.004 & 2.87 & $1.15-7.11$ & 0.023 \\
\hline $\mathrm{T} 4$ versus $\mathrm{T} 2$ & 0.86 & $0.43-1.69$ & 0.657 & 0.87 & $0.35-2.18$ & 0.763 \\
\hline
\end{tabular}

T1: patients who received no treatment other than dialysis. T2: patients who received NSF specific treatment other than renal transplantation. T3: patients who received only renal transplantation. T4: patients who received NSF specific treatment followed by renal transplantation. HR: Hazard ratio. CI $95 \%$ : confidence interval 95\%. $P$ : probability value.

a further evaluation to determine the duration of treatment. Imatinib mesylate has been tried as a single agent and showed marked improvement in NSF patients [112]. There are two case reports demonstrating success with using STS as well $[22,67]$.

It appears that renal function may be correlated with the course of NSF since remission has occurred after the recovery of renal function following renal transplantation or from resolution of an acute kidney injury $[4,23,24]$ and the gradual reversal of the disease in patients not requiring dialysis. Our review of the literature showed that there are 26 NSF patients who received a renal transplant, of which 19 patients showed improvement after transplantation, leading to a response rate of $73.08 \%$. This represents a higher number of successfully treated NSF patients when compared to other treatments used thus far. The response rate observed in the group which received renal transplantation is likely to be as a result of restoration of renal function, although other factors may have contributed as well. The half-life of gadolinium in patients with normal kidney function is approximately 90 minutes, but in patients with advanced renal impairment, the elimination half-life can be prolonged to more than 30 hours [113]. Although, there is no evidence that hemodialysis immediately after gadolinium exposure lowers the risk or severity of NSF, studies have reported that gadolinium removal was up to $99 \%$ after three dialysis sessions [114-116]. Restoration of kidney function results in Gd excretion and detection in the urine, even if the contrast agent was administered up to three years prior to transplantation [54, 117], suggesting that mobilization from tissue and bone deposits $[115,118]$ can occur after transplantation. This weakens the evidence regarding intensive hemodialysis after exposure. If $\mathrm{Gd}$ was indeed the trigger for NSF, the removal of the offending agent should, in theory, ameliorate the inflammation. 
TABLE 3: Comparison between responders and non responders.

\begin{tabular}{|c|c|c|c|c|c|}
\hline \multirow{2}{*}{ Noncategorical variables } & \multicolumn{2}{|c|}{ Improved } & \multicolumn{2}{|c|}{ Did not improve } & \multirow{2}{*}{$P$} \\
\hline & Mean & SE & Mean & SE & \\
\hline Age in years & 44.2 & 1.7 & 54.3 & 1 & $<0.001$ \\
\hline Dialysis duration in months & 32.8 & 7.3 & 56.3 & 5.1 & $<0.001$ \\
\hline Duration to treat in weeks & 31.1 & 6.1 & 10.9 & 3.6 & $<0.001$ \\
\hline Followup duration in weeks & 63.1 & 6.8 & 55.6 & 5.1 & 0.357 \\
\hline \multirow{2}{*}{ Categorical variables } & \multicolumn{2}{|c|}{ Improved } & \multicolumn{2}{|c|}{ Did not improve } & $D$ \\
\hline & $N$ & $\%$ & $N$ & $\%$ & $P$ \\
\hline \multicolumn{6}{|l|}{ Gender (25 missing data) } \\
\hline Male & 39 & 50 & 89 & 45.6 & \multirow{2}{*}{0.514} \\
\hline Female & 39 & 50 & 106 & 54.4 & \\
\hline \multicolumn{6}{|l|}{ Race (204 missing data) } \\
\hline White & 24 & 77.4 & 42 & 66.7 & \multirow{3}{*}{0.519} \\
\hline African American & 3 & 9.7 & 11 & 17.5 & \\
\hline Others & 4 & 12.9 & 10 & 15.9 & \\
\hline \multicolumn{6}{|c|}{ Prior renal transplantation ( 2 missing data) } \\
\hline Prior transplantation & 29 & 34.9 & 38 & 17.8 & \multirow{2}{*}{0.001} \\
\hline No prior transplantation & 54 & 65.1 & 175 & 82.2 & \\
\hline
\end{tabular}

T1: patients who received no treatment other than dialysis. T2: patients who received NSF specific treatment other than renal transplantation. T3: patients who received only renal transplantation. T4: patients who received NSF specific treatment followed by renal transplantation. N: number of patients. SE: standard error. $P$ : probability value.

TABLE 4: Transplant patients who responded and those who did not.

\begin{tabular}{|c|c|c|c|c|c|}
\hline \multirow{2}{*}{ Noncategorical variables } & \multicolumn{2}{|c|}{ Improved } & \multicolumn{2}{|c|}{ Did not improve } & \multirow{2}{*}{$P$} \\
\hline & Mean & SE & Mean & SE & \\
\hline Age in years & 41.5 & 4.4 & 51 & 7.3 & 0.193 \\
\hline Duration to treat in weeks & 67.5 & 16.2 & 97.5 & 26.7 & 0.355 \\
\hline Followup duration in weeks & 57.5 & 16.2 & 64.3 & 28.1 & 0.549 \\
\hline \multirow{2}{*}{ Categorical variables } & \multicolumn{2}{|c|}{ Improved } & \multicolumn{2}{|c|}{ Did not improve } & $P$ \\
\hline & $N$ & $\%$ & $N$ & $\%$ & $P$ \\
\hline \multicolumn{6}{|l|}{ Gender (3 missing data) } \\
\hline Male & 6 & 37.5 & 3 & 42.86 & \multirow{2}{*}{0.809} \\
\hline Female & 10 & 62.5 & 4 & 57.14 & \\
\hline \multicolumn{6}{|c|}{ Dialysis duration (3 missing data) } \\
\hline$<4$ years & 16 & 94.12 & 3 & 50 & \multirow{2}{*}{0.014} \\
\hline$=$ or $>4$ years & 1 & 5.88 & 3 & 50 & \\
\hline \multicolumn{6}{|l|}{ Prior renal transplantation } \\
\hline Prior transplantation & 4 & 21.05 & 1 & 14.29 & \multirow{2}{*}{0.698} \\
\hline No prior transplantation & 15 & 78.95 & 6 & 85.71 & \\
\hline \multicolumn{6}{|l|}{ Other treatments } \\
\hline Transplantation alone & 8 & 42.11 & 1 & 14.29 & \multirow{2}{*}{0.186} \\
\hline Other treatment used & 11 & 57.89 & 6 & 85.71 & \\
\hline
\end{tabular}

T1: patients who received no treatment other than dialysis. T2: patients who received NSF specific treatment other than renal transplantation. T3: patients who received only renal transplantation. T4: patients who received NSF specific treatment followed by renal transplantation. N: number of patients. SE: standard error. $P$ : probability value. 
Topical, intralesional, or oral glucocorticoid therapy and cyclophosphamide have, in general, shown no benefit in some studies $[4,8]$. To the contrary, our observation suggests that immunosuppressive agents, including steroids, may play an important role in treating patients with NSF as the results favor a higher clinical response rate to transplantation. It has been demonstrated that NSF patients express phospho-70-s6 kinase and transforming growth factor-beta (TGF- $\beta$ ), which are targets to rapamycin and mycophenolate (MMF) therapy, respectively. It is possible that there is a downregulation of these proteins in the post-transplantation period, halting the progression of inflammation. However, MMF therapy alone may not confer complete benefit unless used in conjunction with renal transplantation [52].

Renal transplantation may offer a hope for a successful treatment in suitable NSF patients, although efficacy is unproven in some reports [119]. A single center-based study by Leung et al. [28] failed to show any benefit with renal transplantation when compared to those patients who remained on dialysis. This observation is contrary to previously published reports $[9,32,105]$. We found that patients who underwent renal transplantation had a higher chance of a positive response, documented as a clinical improvement, when compared to patients who either continued on maintenance dialysis or those who received alternative forms of treatment.

It has been previously reported by Swartz et al. [23] that there is no association between the risk of development of NSF and patients' age, sex, race, or etiology of renal disease. Our analysis of the literature found that age plays an important role in determining which patients were likely to respond to treatment and have a favorable outcome. Those patients who responded to any treatment were younger and had a shorter dialysis vintage $(P<0.001)$. Interestingly, patients who improved had a longer time to treat $(P<$ 0.001 ). This could be explained by the high percentage of response in the renal transplant group that had the longest time to treat. A possible explanation is that ESRD and dialysis are proinflammatory states [120]. Many factors play a role in the inflammatory state including membrane bioincompatibility, the use of unpure or nonsterile dialysate, and poor dialysis adequacy. Frequency and duration of dialysis was also found to contribute to the inflammatory state in these patients [121-123]. C-reactive protein (CRP) and IL-6 are the most commonly used biomarkers to determine the uremic inflammatory state in ESRD patients. Panichi et al. estimated CRP levels at baseline and at 6 months in long-term HD patients on various modalities using different dialyzer membranes. This analysis showed that baseline CRP values were high $(>5 \mathrm{mg} / \mathrm{L})$ in $47 \%$ of the patients and remained elevated even up to 6 months, which was dependent on the type of the extracorporeal modality (hemodiafiltration versus hemodialysis) and membrane used [124]. Another study involving pediatric patients on maintenance HD demonstrated that 30 minutes after HD treatment, the levels of TNFalpha and IL-1-beta were significantly higher when compared to their pre-HD levels $(P=0.0008)$. Likewise, a positive correlation between dialysis duration and serum levels of CRP $(P<0.001)$, IL6 $(P<0.001)$, and IL-10 $(P=0.03)$ was also noticed [125]. This was thought to be due to a persistent uremic state. Gadolinium, either in the free ionic state, $\mathrm{Gd}^{+}$or $\mathrm{Gd}$-chelate complex form, stimulates the release of cytokines from activated macrophages in skin and peripheral monocytes in blood, respectively. The released cytokine shower, in turn, triggers the bone marrow derived circulating fibrocytes to induce fibrosis in NSF. Collectively, this suggests that dialysis vintage and an inflammatory state are complimentary to one another. In relation to NSF, it is possible that dialysis vintage in the presence of gadolinium maintains a proinflammatory state which promotes a continuous supply of cytokines in the circulation leading to the prolongation of the inflammatory lesions. We found a statistically significant relationship between dialysis vintage and response to treatment $(P<0.001)$. Analysis of 23 patients ( 3 patients with missing data) who received renal transplantation showed that a better response was observed in those who were dialyzed for less than four years $(P=$ 0.014).

The major weakness in our observational study is publication bias. Since no clinical trial establishing the link between Gd and NSF can ever be conducted in human subjects, we are limited to the existing database of published cases to draw conclusions and render treatment. In fact, most of the literature on NSF is in these forms of publications. Furthermore, journals tend to publish reports showing predominantly positive results. The cases that have been reported in the literature provide limited details with respect to the immunosuppressants used or the type of transplant (i.e., live donor versus cadaveric) received by the patient. There may be other confounding factors that may not have been accounted for. The follow-up period following the success of a treatment modality has not been well delineated in most of the case reports. Therefore, there exists a possibility of the recurrence of NSF that may not have been accounted for. We recognized these issues and hence included all cases of NSF including the reports showing both positive and negative results regarding each treatment modality to minimize publication bias. Every attempt was made to include as many unique patients as we could, resulting in 298 patients, which is approximately $80 \%$ of the number of patients' registry at Yale University.

\section{Conclusion}

Nephrogenic systemic fibrosis is a debilitating disease in patients with impaired renal function. Currently, there is no standard treatment, but improvement has been reported after restoration of kidney function. We compared the clinical response rates to various treatments and found that the renal transplantation group had a higher chance of clinical response to treatment when compared to dialysis alone or to any other treatment. Henceforth, based on our analysis, it appears that the renal transplantation is likely a beneficiary treatment modality that can be offered to NSF patients.

\section{Conflict of Interests}

The authors declare that they have no conflict of interests. 


\section{References}

[1] S. E. Cowper, Nephrogenic Fibrosing Dermopathy, ICNSFR, 2001-2009, http://www.icnsfr.org/.

[2] R. Kafi, G. J. Fisher, T. Quan et al., "UV-A1 phototherapy improves nephrogenic fibrosing dermopathy," Archives of Dermatology, vol. 140, no. 11, pp. 1322-1324, 2004.

[3] S. A. Jiménez, C. M. Artlett, N. Sandorfi et al., "Dialysisassociated systemic fibrosis (nephrogenic fibrosing dermopathy): study of inflammatory cells and transforming growth factor $\beta 1$ expression in affected skin," Arthritis and Rheumatism, vol. 50, no. 8, pp. 2660-2666, 2004.

[4] F. A. Mendoza, C. M. Artlett, N. Sandorfi, K. Latinis, S. PieraVelazquez, and S. A. Jimenez, "Description of 12 cases of nephrogenic fibrosing dermopathy and review of the literature," Seminars in Arthritis and Rheumatism, vol. 35, no. 4, pp. 238249, 2006.

[5] P. Evenepoel, M. Zeegers, S. Segaert et al., "Nephrogenic fibrosing dermopathy: a novel, disabling disorder in patients with renal failure," Nephrology Dialysis Transplantation, vol. 19, no. 2, pp. 469-473, 2004.

[6] S. L. Moschella, J. Kay, B. T. Mackool, and V. Liu, "Case records of the Massachusetts General Hospital. Weekly clinicopathological exercises. Case 35-2004. A 68-year-old man with endstage renal disease and thickening of the skin," The New England Journal of Medicine, vol. 351, no. 21, pp. 2219-2227, 2004.

[7] S. E. Cowper, H. S. Robin, S. M. Steinberg, L. D. Su, S. Gupta, and P. E. LeBoit, "Scleromyxoedema-like cutaneous diseases in renal-dialysis patients," The Lancet, vol. 356, no. 9234, pp. 10001001, 2000.

[8] V. Hubbard, A. Davenport, M. Jarmulowicz, and M. Rustin, "Scleromyxoedema-like changes in four renal dialysis patients," British Journal of Dermatology, vol. 148, no. 3, pp. 563-568, 2003.

[9] T. Grobner, "Gadolinium-a specific trigger for the development of nephrogenic fibrosing dermopathy and nephrogenic systemic fibrosis?" Nephrology Dialysis Transplantation, vol. 21, no. 4, pp. 1104-1108, 2006.

[10] M. R. Prince, H. Zhang, M. Morris et al., "Incidence of nephrogenic systemic fibrosis at two large medical centers," Radiology, vol. 248, no. 3, pp. 807-816, 2008.

[11] E. Altun, D. R. Martin, R. Wertman, A. Lugo-Somolinos, E. R. Fuller III, and R. C. Semelka, "Nephrogenic systemic fibrosis: change in incidence following a switch in gadolinium agents and adoption of a gadolinium policy-report from two U.S. universities," Radiology, vol. 253, no. 3, pp. 689-696, 2009.

[12] P. Marckmann, L. Skov, K. Rossen et al., "Nephrogenic systemic fibrosis: suspected causative role of gadodiamide used for contrast-enhanced magnetic resonance imaging," Journal of the American Society of Nephrology, vol. 17, no. 9, pp. 2359-2362, 2006.

[13] E. A. Sadowski, L. K. Bennett, M. R. Chan et al., "Nephrogenic systemic fibrosis: risk factors and incidence estimation," Radiology, vol. 243, no. 1, pp. 148-157, 2007.

[14] T. A. Collidge, P. C. Thomson, P. B. Mark et al., "Gadoliniumenhanced MR imaging and nephrogenic systemic fibrosis: retrospective study of a renal replacement therapy cohort," Radiology, vol. 245, no. 1, pp. 168-175, 2007.

[15] A. Deo, M. Fogel, and S. E. Cowper, "Nephrogenic systemic fibrosis: a population study examining the relationship of disease development to gadolinium exposure," Clinical Journal of the American Society of Nephrology, vol. 2, no. 2, pp. 264-267, 2007.
[16] D. J. Todd, A. Kagan, L. B. Chibnik, and J. Kay, "Cutaneous changes of nephrogenic systemic fibrosis: predictor of early mortality and association with gadolinium exposure," Arthritis and Rheumatism, vol. 56, no. 10, pp. 3433-3441, 2007.

[17] H. J. Chung and K. Y. Chung, "Nephrogenic fibrosing dermopathy: response to high-dose intravenous immunoglobulin," British Journal of Dermatology, vol. 150, no. 3, pp. 596-597, 2004.

[18] P. W. Baron, K. Cantos, D. J. Hillebrand et al., "Nephrogenic fibrosing dermopathy after liver transplantation successfully treated with plasmapheresis," American Journal of Dermatopathology, vol. 25, no. 3, pp. 204-209, 2003.

[19] S. Läuchli, C. Zortea-Caflisch, F. O. Nestle, G. Burg, and W. Kempf, "Nephrogenic fibrosing dermopathy treated with extracorporeal photopheresis," Dermatology, vol. 208, no. 3, pp. 278-280, 2004.

[20] R. Kintossou, M. D’Incan, D. Chauveau et al., "Nephrogenic fibrosing dermopathy treated with extracorporeal photopheresis: role of gadolinium?" Annales de Dermatologie et de Venereologie, vol. 134, no. 8-9, pp. 667-671, 2007.

[21] J. Kay and W. A. High, "Imatinib mesylate treatment of nephrogenic systemic fibrosis," Arthritis and Rheumatism, vol. 58, no. 8, pp. 2543-2548, 2008.

[22] D. Kadiyala, D. A. Roer, and M. A. Perazella, "Nephrogenic systemic fibrosis associated with gadoversetamide exposure: treatment with sodium thiosulfate," American Journal of Kidney Diseases, vol. 53, no. 1, pp. 133-137, 2009.

[23] R. D. Swartz, L. J. Crofford, S. H. Phan, R. W. Ike, and L. D. Su, "Nephrogenic fibrosing dermopathy: a novel cutaneous fibrosing disorder in patients with renal failure," American Journal of Medicine, vol. 114, no. 7, pp. 563-572, 2003.

[24] L. R. Essary and M. R. Wick, "Cutaneous calciphylaxis: an underrecognized clinicopathologic entity," American Journal of Clinical Pathology, vol. 113, no. 2, pp. 280-287, 2000.

[25] M. Panesar, S. Banerjee, and G. W. Barone, "Clinical improvement of nephrogenic systemic fibrosis after kidney transplantation," Clinical Transplantation, vol. 22, no. 6, pp. 803-808, 2008.

[26] G. Schieren, N. Wirtz, P. Altmeyer, L. C. Rump, S. M. Weiner, and A. Kreuter, "Nephrogenic systemic fibrosis-a rapidly progressive disabling disease with limited therapeutic options," Journal of the American Academy of Dermatology, vol. 61, no. 5, pp. 868-874, 2009.

[27] K. Wiedemeyer, H. Kutzner, J. L. Abraham et al., "The evolution of osseous metaplasia in localized cutaneous nephrogenic systemic fibrosis: a case report," American Journal of Dermatopathology, vol. 31, no. 7, pp. 674-681, 2009.

[28] N. Leung, A. Shaikh, F. G. Cosio et al., "The outcome of patients with nephrogenic systemic fibrosis after successful kidney transplantation," American Journal of Transplantation, vol. 10, no. 3, pp. 558-562, 2010.

[29] J. M. Mackay-Wiggan, D. J. Cohen, M. A. Hardy, E. H. Knobler, and M. E. Grossman, "Nephrogenic fibrosing dermopathy (scleromyxedema-like illness of renal disease)," Journal of the American Academy of Dermatology, vol. 48, no. 1, pp. 55-60, 2003.

[30] J. G. Hancox, Y. M. Mengesha, O. P. Sangueza, and G. Yosipovitch, "Nephrogenic fibrosing dermopathy after five days of hemodialysis," Journal of Drugs in Dermatology, vol. 2, no. 5, pp. 550-553, 2003.

[31] M. A. Perazella, S. Ishibe, M. A. Perazella, and R. F. Reilly, "Nephrogenic fibrosing dermopathy: an unusual skin condition associated with kidney disease," Seminars in Dialysis, vol. 16, no. 3, pp. 276-280, 2003. 
[32] F. Jan, J. M. Segal, J. Dyer, P. LeBoit, E. Siegfried, and I. J. Frieden, "Nephrogenic fibrosing dermopathy: two pediatric cases," Journal of Pediatrics, vol. 143, no. 5, pp. 678-681, 2003.

[33] J. M. Levine, R. A. Taylor, L. B. Elman et al., "Involvement of skeletal muscle in dialysis-associated systemic fibrosis (nephrogenic fibrosing dermopathy)," Muscle and Nerve, vol. 30, no. 5, pp. 569-577, 2004.

[34] C. Hauser, G. Kaya, and C. Chizzolini, "Nephrogenic fibrosing dermopathy in a renal transplant recipient with tubulointerstitial nephritis and uveitis," Dermatology, vol. 209, no. 1, pp. 50$52,2004$.

[35] A. W. H. Tan, S. H. Tan, T. Y. Lian, and S. K. Ng, "A case of nephrogenic fibrosing dermopathy," Annals of the Academy of Medicine Singapore, vol. 33, no. 4, pp. 527-529, 2004.

[36] S. M. Jain, S. Wesson, A. Hassanein et al., "Nephrogenic fibrosing dermopathy in pediatric patients," Pediatric Nephrology, vol. 19, no. 4, pp. 467-470, 2004.

[37] J. M. Gremmels and G. A. Kirk, "Two patients with abnormal skeletal muscle uptake of Tc-99m hydroxymethylene diphosphonate following liver transplant: nephrogenic fibrosing dermopathy and graft vs host disease," Clinical Nuclear Medicine, vol. 29, no. 11, pp. 694-697, 2004.

[38] H. Chiu, G. Wells, H. Carag, E. Canova, and R. J. Firpi, "Nephrogenic fibrosing dermopathy: a rare entity in patients awaiting liver transplantation," Liver Transplantation, vol. 10, no. 3, pp. 465-466, 2004.

[39] V. P. Sreenarasimhaiah, W. W. Brown, C. Cortese et al., "A report on four new cases of nephrogenic fibrosing dermopathy in chronic hemodialysis patients," Hemodialysis International, vol. 8, no. 4, pp. 404-408, 2004.

[40] K. Hershko, C. Hull, L. Ettefagh et al., "A variant of nephrogenic fibrosing dermopathy with osteoclast-like giant cells: a syndrome of dysregulated matrix remodeling?" Journal of Cutaneous Pathology, vol. 31, no. 3, pp. 262-265, 2004.

[41] G. Obermoser, M. Emberger, M. Wieser, and B. Zelger, "Nephrogenic fibrosing dermopathy in two patients with systemic lupus erythematosus," Lupus, vol. 13, no. 8, pp. 609-612, 2004.

[42] N. Ortonne, D. Lipsker, F. Chantrel, N. Boehm, E. Grosshans, and B. Cribier, "Presence of CD45RO+ CD34+ cells with collagen synthesis activity in nepharogenic fibrosing dermopathy: a new pathogenic hypothesis," British Journal of Dermatology, vol. 150, no. 5, pp. 1050-1052, 2004.

[43] I. Dundová, V. Treska, V. Simanek, and M. Michal, "Nephrogenic fibrosing dermopathy: a case study," Transplantation Proceedings, vol. 37, no. 10, pp. 4187-4190, 2005.

[44] A. Dupont, V. Majithia, S. Ahmad, and R. McMurray, "Nephrogenic fibrosing dermopathy, a new mimicker of systemic sclerosis," American Journal of the Medical Sciences, vol. 330, no. 4, pp. 192-194, 2005.

[45] A. S. Glaich, P. T. Martinelli, R. F. Markus, and S. Hsu, "Generalized elastolysis following nephrogenic fibrosing dermopathy," Journal of the American Academy of Dermatology, vol. 53, no. 1, pp. 174-176, 2005.

[46] S. R. Daram, C. M. Cortese, and B. Bastani, "Nephrogenic fibrosing dermopathy/nephrogenic systemic fibrosis: report of a new case with literature review," American Journal of Kidney Diseases, vol. 46, no. 4, pp. 754-759, 2005.
[47] T. Schmook, K. Budde, C. Ulrich, H. H. Neumayer, L. Fritsche, and E. Stockfleth, "Successful treatment of nephrogenic fibrosing dermopathy in a kidney transplant recipient with photodynamic therapy," Nephrology Dialysis Transplantation, vol. 20, no. 1, pp. 220-222, 2005.

[48] M. Gilliet, A. Cozzio, G. Burg, and F. O. Nestle, "Successful treatment of three cases of nephrogenic fibrosing dermopathy with extracorporeal photopheresis," British Journal of Dermatology, vol. 152, no. 3, pp. 531-536, 2005.

[49] S. E. Gibson, C. F. Farver, and R. A. Prayson, "Multiorgan involvement in nephrogenic fibrosing dermopathy: an autopsy case and review of the literature," Archives of Pathology and Laboratory Medicine, vol. 130, no. 2, pp. 209-212, 2006.

[50] J. B. DiCarlo, E. A. Gupta, and A. R. Solomon, "A pediatric case of nephrogenic fibrosing dermopathy: improvement after combination therapy," Journal of the American Academy of Dermatology, vol. 54, no. 5, pp. 914-916, 2006.

[51] T. B. Cassis, J. M. Jackson, G. B. Sonnier, and J. P. Callen, "Nephrogenic fibrosing dermopathy in a patient with acute renal failure never requiring dialysis," International Journal of Dermatology, vol. 45, no. 1, pp. 56-59, 2006.

[52] A. Auron, L. Shao, and B. A. Warady, "Nephrogenic fibrosing dermopathy in children," Pediatric Nephrology, vol. 21, no. 9, pp. 1307-1311, 2006.

[53] M. Maloo, P. Abt, R. Kashyap et al., "Nephrogenic systemic fibrosis among liver transplant recipients: a single institution experience and topic update," American Journal of Transplantation, vol. 6, no. 9, pp. 2212-2217, 2006.

[54] C. Thakral, J. Alhariri, and J. L. Abraham, "Long-term retention of gadolinium in tissues from nephrogenic systemic fibrosis patient after multiple gadolinium-enhanced MRI scans: case report and implications," Contrast Media and Molecular Imaging, vol. 2, no. 4, pp. 199-205, 2007.

[55] S. Keyrouz and S. A. Rudnicki, "Neuromuscular involvement in nephrogenic systemic fibrosis," Journal of Clinical Neuromuscular Disease, vol. 9, no. 2, pp. 297-302, 2007.

[56] P. P. M. Cheung and A. K. Dorai Raj, "Nephrogenic fibrosing dermopathy: a new clinical entity mimicking scleroderma," Internal Medicine Journal, vol. 37, no. 2, pp. 139-141, 2007.

[57] A. S. Weiss, M. S. Lucia, and I. Teitelbaum, "A case of nephrogenic fibrosing dermopathy/nephrogenic systemic fibrosis," Nature Clinical Practice Nephrology, vol. 3, no. 2, pp. 111-115, 2007.

[58] Y. L. Lim, H. Y. Lee, S. C. S. Low, L. P. Chan, N. S. G. Goh, and S. M. Pang, "Possible role of gadolinium in nephrogenic systemic fibrosis: report of two cases and review of the literature," Clinical and Experimental Dermatology, vol. 32, no. 4, pp. 353-358, 2007.

[59] I. M. Wahba, E. L. Simpson, and K. White, "Gadolinium is not the only trigger for nephrogenic systemic fibrosis: insights from two cases and review of the recent literature," American Journal of Transplantation, vol. 7, no. 10, pp. 2425-2432, 2007.

[60] I. M. Wahba, K. White, M. Meyer, and E. L. Simpson, “The case for ultraviolet light therapy in nephrogenic fibrosing dermopathy-report of two cases and review of the literature," Nephrology Dialysis Transplantation, vol. 22, no. 2, pp. 631-636, 2007.

[61] M. Sanchez-Ross, R. Snyder, M. I. Colome-Grimmer, M. Blumberg, Y. Huttenbach, and S. Raimer, "Nephrogenic fibrosing dermopathy in a patient with systemic lupus erythematosus and acute lupus nephritis," Pediatric Dermatology, vol. 24, no. 5, pp. E36-E39, 2007. 
[62] H. Pieringer, B. Schmekal, O. Janko, and G. Biesenbach, “Treatment with corticosteroids does not seem to benefit nephrogenic systemic fibrosis," Nephrology Dialysis Transplantation, vol. 22, no. 10, p. 3094, 2007.

[63] C. W. Tsai, C. C. Chao, V. C. Wu, C. H. Hsiao, and Y. M. Chen, "Nephrogenic fibrosing dermopathy in a peritoneal dialysis patient," Kidney International, vol. 72, no. 10, p. 1294, 2007.

[64] N. B. Aires, M. N. Sotto, and M. M. S. Nico, "Nephrogenic fibrosing dermopathy: report of two cases," Acta DermatoVenereologica, vol. 87, no. 6, pp. 521-524, 2007.

[65] K. Hamilton-Persaud, L. D. Ezell, and J. G. Macklin, "Nephrogenic fibrosing dermopathy/nephrogenic systemic fibrosis," Nephrology Nursing Journal, vol. 34, no. 3, pp. 283-288, 2007.

[66] J. A. Moreno-Romero, S. Segura, J. J. M. Mascaro Jr. et al., "Nephrogenic systemic fibrosis: a case series suggesting gadolinium as a possible aetiological factor," British Journal of Dermatology, vol. 157, no. 4, pp. 783-787, 2007.

[67] P. Yerram, G. Saab, P. R. Karuparthi, M. R. Hayden, and R. Khanna, "Nephrogenic systemic fibrosis: a mysterious disease in patients with renal failure-role of gadolinium-based contrast media in causation and the beneficial effect of intravenous sodium thiosulfate," Clinical Journal of the American Society of Nephrology, vol. 2, no. 2, pp. 258-263, 2007.

[68] D. S. Goddard, C. C. Magee, A. J. F. Lazar, and D. M. Miller, "Nephrogenic fibrosing dermopathy with recurrence after allograft failure," Journal of the American Academy of Dermatology, vol. 56, no. 5, supplement, pp. S109-S111, 2007.

[69] A. Khurana, V. M. Runge, M. Narayanan, J. F. Greene Jr., and A. E. Nickel, "Nephrogenic systemic fibrosis: a review of 6 cases temporally related to gadodiamide injection (Omniscan)," Investigative Radiology, vol. 42, no. 2, pp. 139-145, 2007.

[70] S. Clorius, K. Technau, T. Watter et al., "Nephrogenic systemic fibrosis following exposure to gadolinium-containing contrast agent," Clinical Nephrology, vol. 68, no. 4, pp. 249-252, 2007.

[71] H. Richmond, J. Zwerner, Y. Kim, and D. Fiorentino, "Nephrogenic systemic fibrosis: relationship to gadolinium and response to photopheresis," Archives of Dermatology, vol. 143, no. 8, pp. 1025-1030, 2007.

[72] R. E. Kalb, T. N. Helm, H. Sperry, C. Thakral, J. L. Abraham, and E. Kanal, "Gadolinium-induced nephrogenic systemic fibrosis in a patient with an acute and transient kidney injury," British Journal of Dermatology, vol. 158, no. 3, pp. 607-610, 2008.

[73] E. Saussereau, C. Lacroix, A. Cattaneo, L. Mahieu, and J. P. Goulle, "Hair and fingernail gadolinium ICP-MS contents in an overdose case associated with nephrogenic systemic fibrosis," Forensic Science International, vol. 176, no. 1, pp. 54-57, 2008.

[74] S. Bainotti, E. Rota, M. Bertrero, O. Tamburrini, A. Balducci, and M. Formica, "Nephrogenic systemic fibrosis: the first Italian gadolinium-proven case," Clinical Nephrology, vol. 70, no. 6, pp. 514-517, 2008.

[75] J. Sharma, A. Mongia, M. Schoenaman, S. Chang, A. D’Angelo, and M. Rao, "Nephrogenic fibrosing dermatopathy, cardiac calcification and pulmonary hypertension in an adolescent on chronic hemodialysis," Indian Journal of Nephrology, vol. 18, no. 2, pp. 70-73, 2008.

[76] B. F. Firoz, C. M. Hunzeker, A. C. Soldano, and A. G. Franks Jr., "Nephrogenic fibrosing dermopathy," Dermatology Online Journal, vol. 14, no. 5, article 11, 2008.

[77] S. Digby, E. MacDuff, K. Blessing, and S. Holmes, "Nephrogenic systemic fibrosis: a histopathological study of eight cases of a recently described entity," Histopathology, vol. 52, no. 4, pp. 531534, 2008.
[78] C. C. Chao, C. C. Yang, C. H. Hsiao, M. K. Pan, C. H. Lin, and S. T. Hsieh, "Nephrogenic systemic fibrosis associated with gadolinium use," Journal of the Formosan Medical Association, vol. 107, no. 3, pp. 270-274, 2008.

[79] S. Sego, "Nephrogenic fibrosing dermopathy: a case study," Nephrology Nursing Journal, vol. 35, no. 1, pp. 67-68, 2008.

[80] P. Marckmann, A. H. Nielsen, and J. J. Sloth, "Possibly enhanced Gd excretion in dialysate, but no major clinical benefit of 3-5 months of treatment with sodium thiosulfate in late stages of nephrogenic systemic fibrosis," Nephrology Dialysis Transplantation, vol. 23, no. 10, pp. 3280-3282, 2008.

[81] K. Shin, S. R. Granter, J. S. Coblyn, and S. Gupta, "Progressive arm and leg stiffness in a patient with chronic renal impairment," Nature Clinical Practice Rheumatology, vol. 4, no. 10, pp. 557-562, 2008.

[82] A. Dhungel, R. Lattupalli, and J. Topf, "Nephrogenic fibrosing dermopathy," The Scientific World Journal, vol. 8, pp. 164-165, 2008.

[83] T. Caccetta and J. J. Chan, "Nephrogenic systemic fibrosis associated with liver transplantation, renal failure and gadolinium," Australasian Journal of Dermatology, vol. 49, no. 1, pp. 48-51, 2008.

[84] N. S. Anavekar, A. H. Chong, R. Norris, J. Dowling, and D. Goodman, "Nephrogenic systemic fibrosis in a gadoliniumnaive renal transplant recipient," Australasian Journal of Dermatology, vol. 49, no. 1, pp. 44-47, 2008.

[85] Y. Nagai, M. Hasegawa, K. Shinmi et al., "Nephrogenic systemic fibrosis with multiple calcification and osseous metaplasia," Acta Dermato-Venereologica, vol. 88, no. 6, pp. 597-600, 2008.

[86] A. Khurana, A. E. Nickel, J. F. Greene Jr., M. Narayanan, W. A. High, and C. J. Foulks, "Successful pregnancy in a hemodialysis patient and marked resolution of her nephrogenic systemic fibrosis," American Journal of Kidney Diseases, vol. 51, no. 6, pp. e29-e32, 2008.

[87] A. Kreuter, T. Gambichler, S. M. Weiner, and G. Schieren, "Limited effects of UV-A1 phototherapy in 3 patients with nephrogenic systemic fibrosis," Archives of Dermatology, vol. 144, no. 11, pp. 1527-1529, 2008.

[88] M. Singh, A. Davenport, I. Clatworthy et al., "A follow-up of four cases of nephrogenic systemic fibrosis: is gadolinium the specific trigger?" British Journal of Dermatology, vol. 158, no. 6, pp. 1358-1362, 2008.

[89] P. Marckmann, "An epidemic outbreak of nephrogenic systemic fibrosis in a Danish hospital," European Journal of Radiology, vol. 66, no. 2, pp. 187-190, 2008.

[90] K. Nakai, K. Takeda, H. Kimura, S. Miura, and A. Maeda, "Nephrogenic systemic fibrosis in a patient on long-term hemodialysis," Clinical Nephrology, vol. 71, no. 2, pp. 217-220, 2009.

[91] J. Song, S. Volkov, C. R. Shea et al., "Nephrogenic systemic fibrosis associated with stromal and vascular calcification, report of two cases," Journal of Cutaneous Pathology, vol. 36, supplement 1, pp. 31-34, 2009.

[92] C. Foss, J. K. Smith, L. Ortiz, C. Hanevold, and L. Davis, "Gadolinium-associated nephrogenic systemic fibrosis in a 9year-old boy," Pediatric Dermatology, vol. 26, no. 5, pp. 579-582, 2009.

[93] K. H. N. Chan, W. Y. M. Tang, K. C. Hau et al., "Nephrogenic systemic fibrosis in a Chinese renal-transplant recipient," Clinical and Experimental Dermatology, vol. 34, no. 2, pp. 244-246, 2009. 
[94] C. F. Lu, C. H. Hsiao, and J. W. Tjiu, "Nephrogenic systemic fibrosis developed after recovery from acute renal failure: gadolinium as a possible aetiological factor," Journal of the European Academy of Dermatology and Venereology, vol. 23, no. 3, pp. 339-340, 2009.

[95] A. F. Koreishi, R. M. Nazarian, A. J. Saenz et al., "Nephrogenic systemic fibrosis: a pathologic study of autopsy cases," Archives of Pathology and Laboratory Medicine, vol. 133, no. 12, pp. 19431948, 2009.

[96] A. Al Habeeb, S. Partington, D. Rosenthal, and S. Salama, "Skin thickening in a hemodialysis patient: a case of nephrogenic fibrosing dermopathy," Journal of Cutaneous Medicine and Surgery, vol. 13, no. 2, pp. 110-114, 2009.

[97] W. C. Chen, S. L. Huang, C. S. Huang et al., "Nephrogenic systemic fibrosis in advanced chronic kidney disease: a single hospital's experience in Taiwan," European Journal of Dermatology, vol. 19, no. 1, pp. 44-49, 2009.

[98] R. S. Gist, D. W. Miller, and T. Warren, "A difficult airway in a patient with nephrogenic sclerosing fibrosis," Anesthesia and Analgesia, vol. 110, no. 2, pp. 555-557, 2010.

[99] C. Wilford, J. D. Fine, A. S. Boyd, S. Sanyal, J. L. Abraham, and S. M. Kantrow, "Nephrogenic systemic fibrosis: report of an additional case with granulomatous inflammation," American Journal of Dermatopathology, vol. 32, no. 1, pp. 71-75, 2010.

[100] Y. Tsushima, E. Kanal, and H. S. Thomsen, "Nephrogenic systemic fibrosis: risk factors suggested from Japanese published cases," British Journal of Radiology, vol. 83, no. 991, pp. 590-595, 2010.

[101] H. Hoppe, S. Spagnuolo, J. M. Froehlich et al., "Retrospective analysis of patients for development of nephrogenic systemic fibrosis following conventional angiography using gadoliniumbased contrast agents," European Radiology, vol. 20, no. 3, pp. 595-603, 2010.

[102] E. Edgar, R. Woltjer, R. Whitham, S. H. Gultekin, S. Watnick, and E. J. Cupler, "Nephrogenic systemic fibrosis presenting as myopathy: a case report with histopathologic correlation," Neuromuscular Disorders, vol. 20, no. 6, pp. 411-413, 2010.

[103] A. A. Lemy, V. del Marmol, A. Kolivras et al., "Revisiting nephrogenic systemic fibrosis in 6 kidney transplant recipients: a single-center experience," Journal of the American Academy of Dermatology, vol. 63, no. 3, pp. 389-399, 2010.

[104] I. S. Reddy, V. K. Somani, G. Swarnalata, and S. Maitra, "Nephrogenic systemic fibrosis following hair-dye ingestion induced acute renal failure," Indian Journal of Dermatology, Venereology and Leprology, vol. 76, no. 4, pp. 400-403, 2010.

[105] M. C. Cuffy, M. Singh, R. Formica et al., "Renal transplantation for nephrogenic systemic fibrosis: a case report and review of the literature," Nephrology Dialysis Transplantation, vol. 26, no. 3, pp. 1099-1101, 2011.

[106] N. Bangsgaard, J. M. Hansen, P. Marckmann, and L. Skov, "Nephrogenic systemic fibrosis symptoms alleviated by renal transplantation," Dialysis and Transplantation, vol. 40, no. 2, pp. 86-87, 2011.

[107] G. J. Fisher, S. Datta, Z. Wang et al., "c-Jun-dependent inhibition of cutaneous procollagen transcription following ultraviolet irradiation is reversed by all-trans retinoic acid," Journal of Clinical Investigation, vol. 106, no. 5, pp. 663-670, 2000.

[108] S. Swaminathan, T. D. Horn, D. Pellowski et al., "Nephrogenic systemic fibrosis, gadolinium, and iron mobilization," The New England Journal of Medicine, vol. 357, no. 7, pp. 720-722, 2007.

[109] M. F. Bellin, "MR contrast agents, the old and the new," European Journal of Radiology, vol. 60, no. 3, pp. 314-323, 2006.
[110] S. Wang, M. C. Wilkes, E. B. Leof, and R. Hirschberg, "Imatinib mesylate blocks a non-Smad TGF- $\beta$ pathway and reduces renal fibrogenesis in vivo," The FASEB Journal, vol. 19, no. 1, pp. 1-11, 2005.

[111] J. H. W. Distler, A. Jüngel, L. C. Huber et al., "Imatinib mesylate reduces production of extracellular matrix and prevents development of experimental dermal fibrosis," Arthritis and Rheumatism, vol. 56, no. 1, pp. 311-322, 2007.

[112] S. Chandran, J. Petersen, C. Jacobs, D. Fiorentino, K. Doeden, and R. A. Lafayette, "Imatinib in the treatment of nephrogenic systemic fibrosis," American Journal of Kidney Diseases, vol. 53, no. 1, pp. 129-132, 2009.

[113] J. M. Idée, M. Port, I. Raynal, M. Schaefer, S. Le Greneur, and C. Corot, "Clinical and biological consequences of transmetallation induced by contrast agents for magnetic resonance imaging: a review," Fundamental and Clinical Pharmacology, vol. 20, no. 6, pp. 563-576, 2006.

[114] S. Okada, K. Katagiri, T. Kumazaki, and H. Yokoyama, "Safety of gadolinium contrast agent in hemodialysis patients," Acta Radiologica, vol. 42, no. 3, pp. 339-341, 2001.

[115] J. Haustein and G. Schumann-Giampieri, "Elimination of GdDTPA by means of hemodialysis," European Journal of Radiology, vol. 11, no. 3, pp. 227-229, 1990.

[116] T. Saitoh, K. Hayasaka, Y. Tanaka, T. Kuno, and Y. Nagura, "Dialyzability of gadodiamide in hemodialysis patients," Radiation Medicine, vol. 24, no. 6, pp. 445-451, 2006.

[117] N. Leung, M. R. Pittelkow, C. U. Lee, J. A. Good, M. M. Hanley, and T. P. Moyer, "Chelation of gadolinium with deferoxamine in a patient with nephrogenic systemic fibrosis," NDT Plus, vol. 2, no. 4, pp. 309-311, 2009.

[118] J. L. Abraham, C. Thakral, L. Skov, K. Rossen, and P. Marckmann, "Dermal inorganic gadolinium concentrations: evidence for in vivo transmetallation and long-term persistence in nephrogenic systemic fibrosis," British Journal of Dermatology, vol. 158, no. 2, pp. 273-280, 2008.

[119] S. E. Cowper, "Nephrogenic systemic fibrosis: the nosological and conceptual evolution of nephrogenic fibrosing dermopathy," American Journal of Kidney Diseases, vol. 46, no. 4, pp. 763765, 2005.

[120] P. Stenvinkel, "Inflammatory and atherosclerotic interactions in the depleted uremic patient," Blood Purification, vol. 19, no. 1, pp. 53-61, 2001.

[121] J. J. Carrero and P. Stenvinkel, "Inflammation in end-stage renal disease-what have we learned in 10 years?" Seminars in Dialysis, vol. 23, no. 5, pp. 498-509, 2010.

[122] G. A. Kaysen, J. A. Dubin, H. G. Müller, L. M. Rosales, and N. W. Levin, "The acute-phase response varies with time and predicts serum albumin levels in hemodialysis patients. The HEMO Study Group," Kidney International, vol. 58, no. 1, pp. 346-352, 2000.

[123] L. Gesualdo, G. Pertosa, G. Grandaliano, and F. P. Schena, "Cytokines and bioincompatibility," Nephrology Dialysis Transplantation, vol. 13, no. 7, pp. 1622-1626, 1998.

[124] V. Panichi, G. M. Rizza, D. Taccola et al., "C-reactive protein in patients on chronic hemodialysis with different techniques and different membranes," Biomedicine \& Pharmacotherapy, vol. 60, no. 1, pp. 14-17, 2006.

[125] S. L. Goldstein, H. Currier, L. Watters, J. M. Hempe, R. D. Sheth, and D. Silverstein, "Acute and chronic inflammation in pediatric patients receiving hemodialysis," Journal of Pediatrics, vol. 143, no. 5, pp. 653-657, 2003. 


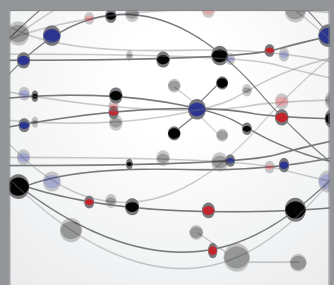

The Scientific World Journal
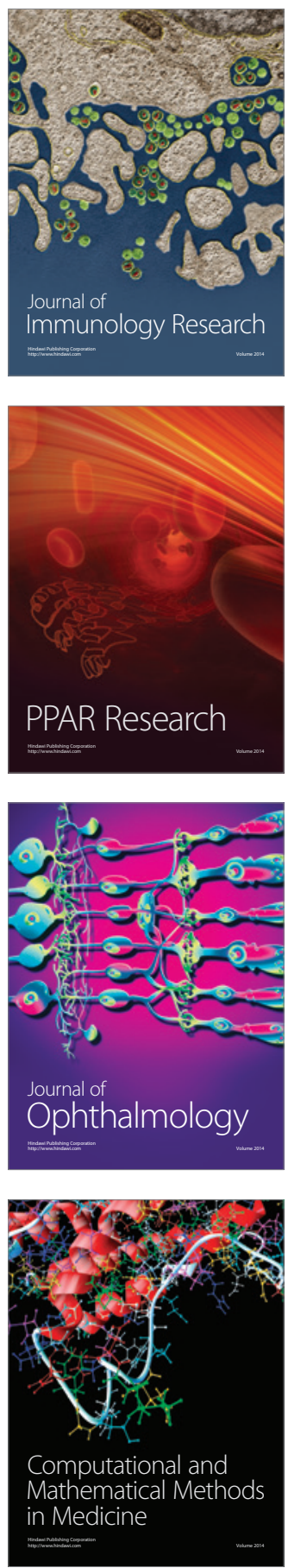

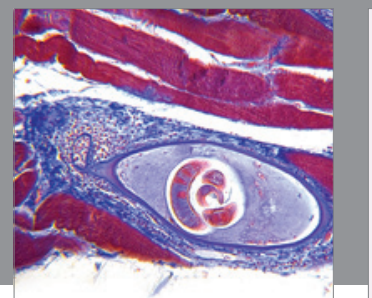

Gastroenterology

Research and Practice
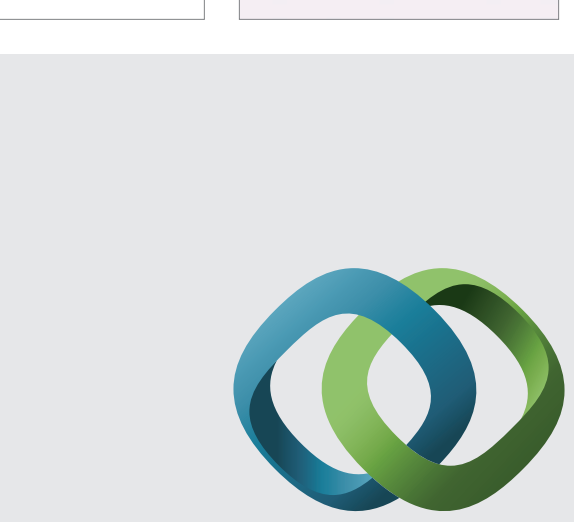

\section{Hindawi}

Submit your manuscripts at

http://www.hindawi.com
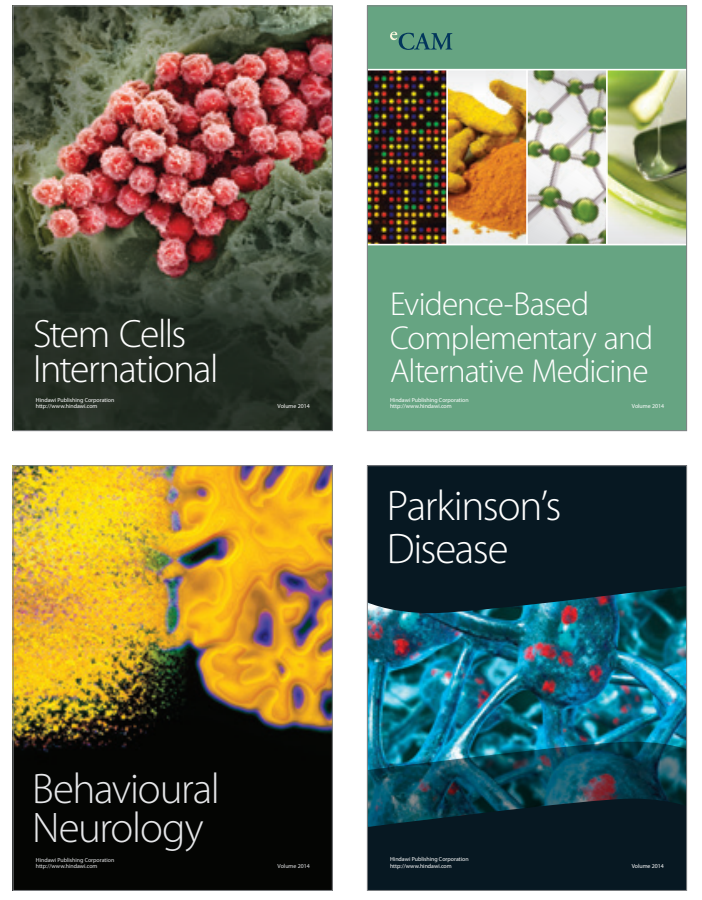
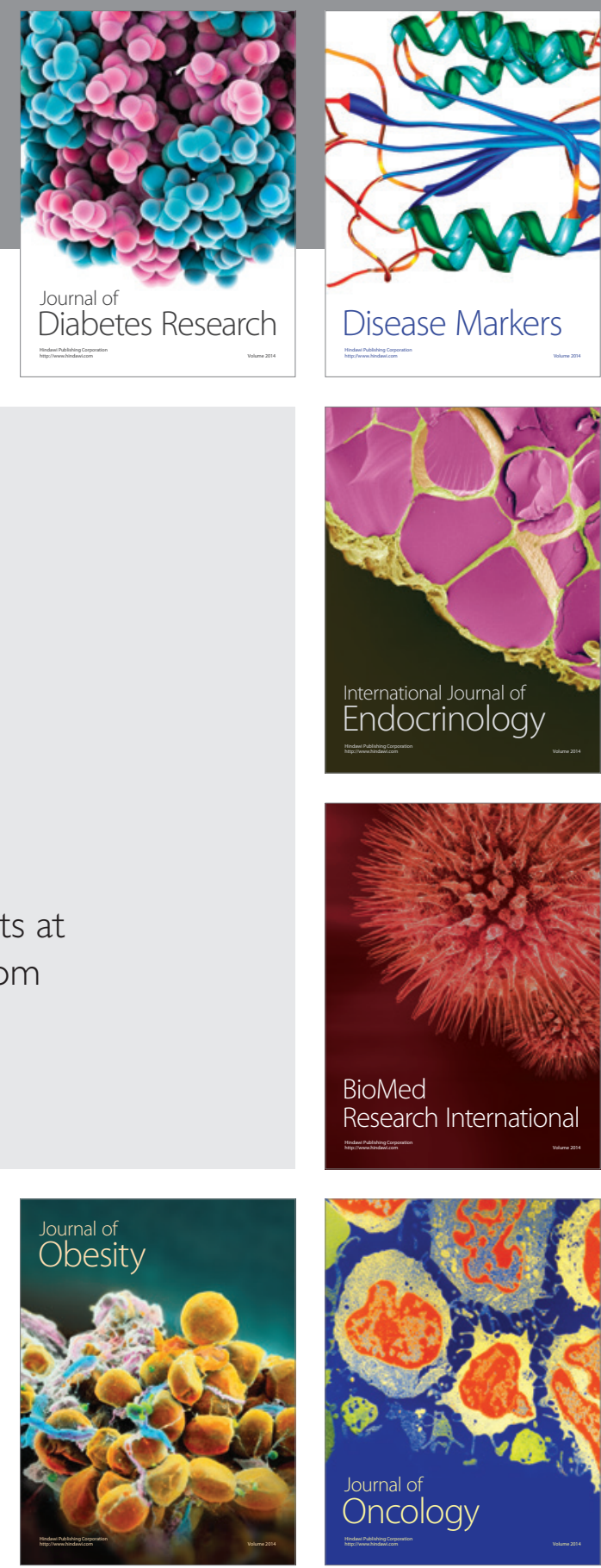

Disease Markers
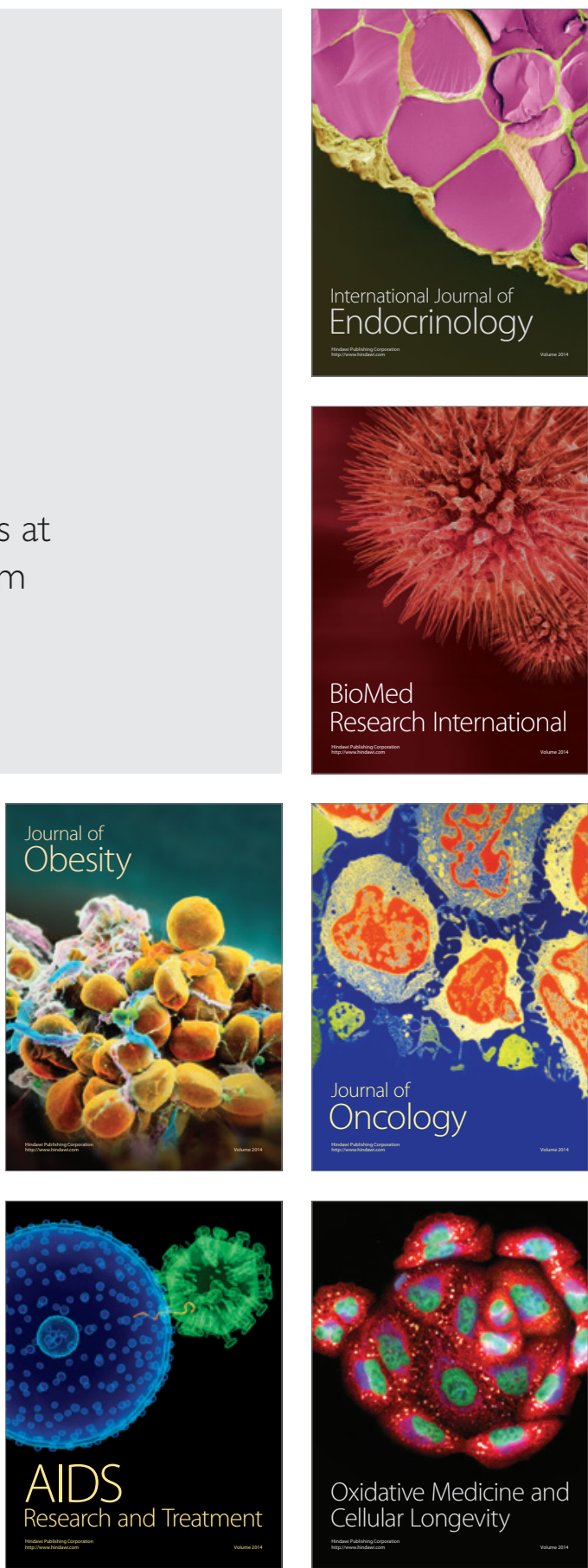